
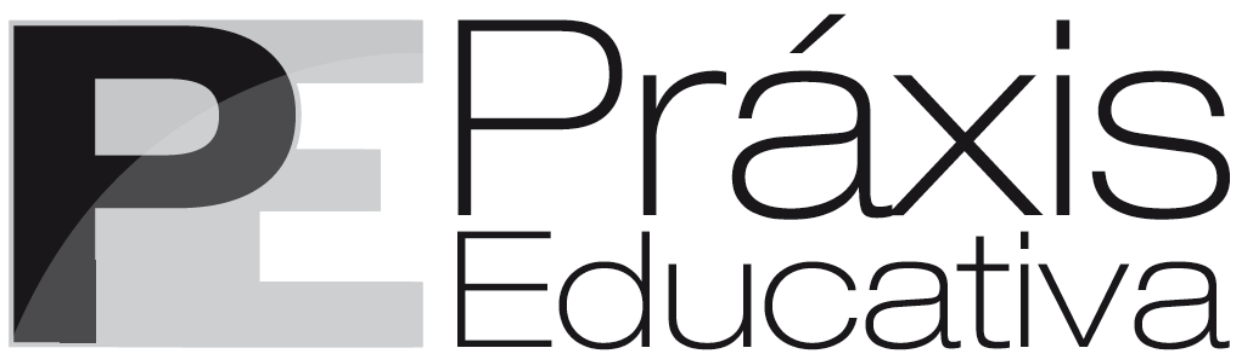

ISSN 1809-4309 (Versão online) DOI: 10.5212/PraxEduc.v.12i2.0010

\title{
A diferença no currículo cultural: por uma Educação (Física) menor ${ }^{*}$
}

\section{The difference in cultural curriculum: for a lesser (Physical) Education}

\section{La diferencia en el currículo del estudio cultural: una Educación (Física) menor}

\author{
Hugo César Bueno Nunes ${ }^{* *}$ \\ Marcos Garcia Neira ${ }^{* * *}$
}

\begin{abstract}
Resumo: O momento atual é contingente, plural, descentralizado, livre das velhas identidades e permeado pelo barulho das vozes que nunca foram ouvidas. Inserida nesse contexto, a escola tenta superar os traços do passado e enfrentar as lutas do presente. No âmbito da Educação Física, o currículo cultural parece querer contribuir com a mentalidade de uma nova era ao questionar a hegemonia das práticas corporais e dos significados dos grupos privilegiados para promover uma pedagogia da diferença. A presente pesquisa analisou as obras mais importantes dessa proposta, identificou os princípios e procedimentos didáticos que a caracterizam e submeteu-os ao confronto com a noção de diferença pura de Gilles Deleuze. Os resultados indicam que o currículo cultural assume a feição de uma Educação (Física) menor quando escuta o que os diferentes têm a dizer e presta atencạ̃o no repertório cultural corporal que os estudantes acessam.
\end{abstract}

Palavras-chave: Diferença. Currículo. Educação Física.

Abstract: The current time is contingent, plural, decentralized, free of old identities and permeated by the noise of voices that have never been heard. Inserted in such context, the school tries to overcome traces of the past and face the struggles of the present. Regarding physical education, the cultural curriculum seems to contribute with the new era mentality by questioning the hegemony of body practices and meanings of the privileged groups to promote the pedagogy of difference. This study analyzed the most important works on this proposal, identifying teaching principles and procedures that characterize it and submitted them to the confrontation with the notion of pure difference by Gilles Deleuze. The results indicate that the cultural curriculum takes the features of a lesser (physical) education when it listens what the 'different ones' have to say and pays attention to the cultural body repertoire that students can access.

Keywords: Difference. Curriculum. Physical Education.

Resumen: El momento presente es contingente, plural, descentralizada, libre de las viejas identidades e impregnado por el sonido de voces que nunca han sido oídas. Insertado en este contexto, la escuela

\footnotetext{
* A pesquisa contou com o apoio da FAPESP e do CNPq.

** Doutorando do Programa de Pós-Graduação em Educação da Universidade de São Paulo (USP). E-mail: $<$ nuneshugo@live.com>.

*** Professor da Faculdade de Educação da Universidade de São Paulo (USP). E-mail: <mgneira@usp.br>.
} 
intenta superar las huellas del pasado y hacer frente a las luchas del presente. En el contexto de la educación física, el programa curricular cultural parece contribuir a la mentalidad de una nueva era de cuestionar la hegemonía de las prácticas corporales y los significados de los grupos privilegiados para promover una pedagogía de la diferencia. Esta investigación analizó las obras más importantes de esta propuesta e identificó los principios y procedimientos didácticos que caracterizan y los sometió al confronto con la noción de la pura diferencia de Gilles Deleuze. Los resultados indican que el currículo cultural asume la apariencia de Educación (Física) menor al escuchar lo que los diferentes tienen que decir y pone atención al repertorio cultural corporal accedido por los estudiantes.

Palabras clave: Diferencia. Currículo. Educación Física.

\section{Introdução}

Estudiosos de variadas correntes enfrentam dificuldades na tentativa de encontrar um tom adequado para abordar o tempo presente, não há nomes que o designem, definam ou classifiquem. O tom deste tempo é caótico, confuso, desordenado; uma dissonância de descontinuidades, de fragmentos, de silêncios: migrações e deslocamentos de populações inteiras, violência racial, enfrentamentos no interior das cidades, a pluralização, a mestiçagem e a segmentação das comunidades, a progressiva destruição e burocratização dos espaços de convivência, a proliferação dos intercâmbios e das comunicações, a afirmação das diferenças em um mundo cada vez mais globalizado. Na visão de Skliar (2003), o caos e a desordem produzem o rompimento e a ruína de todos os projetos da modernidade que o homem ocidental quis construir, ou seja, um mundo ordenado à sua imagem e semelhança, à medida de seu saber, de seu poder e de sua vontade, por meio de sua expansão racional, civilizadora e colonizadora.

Juntamente à crise global intensificada pelas novas tecnologias, a identidade do sujeito na sociedade, que por um período foi fixada em padrões determinados, dissolveu-se em virtude das novas relações que vêm sendo estabelecidas. Bauman (2003) nomeia o atual período histórico de modernidade líquida; Sousa Santos (2010), de sociedade pós-moderna, e Hall (2011), de modernidade tardia.

As sociedades da modernidade tardia são caracterizadas pela 'diferença', são atravessadas por inúmeras divisões e antagonismos que produzem diferentes posições de sujeito. Se considerarmos que a escola (ao lado da família) foi responsabilizada pela formação de sujeitos para esta sociedade, falhará qualquer iniciativa de construção de uma experiência educativa que desconsidere a presença da diferença.

A escola contemporânea é um espaço de direito de todos/as, onde os estudantes possam ter reconhecidas suas singularidades e fomentadas suas potencialidades, no entanto, devido a seu enraizamento moderno, a escola muitas vezes acaba por desvalorizar e apagar as diferenças. Pensar uma educação pautada no viés da diferença cultural passa a ser de fundamental importância para que possamos olhar para os estudantes e vê-los como seres singulares, com suas particularidades e potencialidades.

Há que se reconhecer as muitas histórias, as várias culturas e os diferentes saberes, para que seja possível desestabilizar as representações estruturadas pela cultura hegemônica. O trabalho pedagógico a partir das diferenças culturais pode ampliar os movimentos escolares que se opõem à subalternização, por não contar com um "sujeito transcendente que sabe", mas sujeitos que tecem saberes e não saberes (ESTEBAN, 2003).

A diferença cultural, concebida como uma prática discursiva atravessada por relações de poder, inviabiliza pensar a educação e, principalmente, o currículo escolar, como meras questões

Práxis Educativa, Ponta Grossa, v. 12, n. 2, p. 464-480, maio/ago. 2017 Disponível em: <http://www.revistas2.uepg.br/index.php/praxiseducativa > 
técnicas, postas e pensadas a priori por especialistas. É preciso descentrá-las, esgarçá-las, produzilas na diferença. Procurando entrelaçar o viés cultural com a perspectiva da filosofia da diferença de Gilles Deleuze, passamos a privilegiar o pensamento enquanto diferença pura e não como o modo representacional que caracterizou a filosofia ocidental. Nesta, o pensamento é atrelado à imagem, à representação, à re-cognição, algo como o reflexo da realidade.

Ao concebermos a diferença em si mesma, o currículo pode ser enunciado como um espaço-tempo onde diferenças culturais e conhecimentos distintos são colocados em constante confronto, buscando irromperem na criação do novo. O currículo passa a ser um local onde as diferenças são traduzidas, uma tradução que modifica as particularidades de cada cultura, obrigando-as a negociar constantemente. Afinal, na visão de Paraíso (2010), o currículo é a própria diferença.

Dada sua importância na constituição do sujeito da educação, o currículo tornou-se campo de estudos e disputas políticas. A teorização curricular mais recente (LOPES; MACEDO, 2011) vem adotando como matrizes epistemológicas a teoria queer, os estudos culturais, o multiculturalismo, os estudos pós-coloniais, o pós-estruturalismo e a filosofia da diferença. Com base nesses campos teóricos, o currículo foi concebido como texto, prática discursiva, produto de microrrelações de poder espalhadas pelo tecido social. O currículo é um modo de significação que produz sentidos para as pessoas e coisas do mundo. Em outras palavras, o currículo, enquanto discurso, cria realidades e inventa sujeitos discentes e docentes.

No âmbito da Educação Física, o esforço para produzir experiências curriculares a partir dessas noções fez surgir o chamado currículo cultural. Concebida como artefato da cultura, tal proposta é um campo de disseminação de sentidos, polissemia e formação de subjetividades que buscam analisar, significar, questionar e dialogar entre e a partir das culturas, tendo as questões relacionadas ao poder como centrais na produção dos significados atribuídos às práticas corporais (NEIRA; NUNES, 2009).

O currículo cultural da Educação Física realiza a leitura da gestualidade materializada nas práticas corporais, sem qualquer julgamento de valor. Não busca o melhor rendimento ou a aquisição e manutenção da saúde, nem tampouco a execução motora considerada adequada. No currículo cultural, as brincadeiras, danças, ginásticas, lutas e esportes são entendidos como textos da cultura, formas de expressar sentimentos, ideias e valores e, consequentemente, são marcadas por relações de classe, etnia, religião, gênero, geração etc.

O currículo cultural valoriza a apreciação como ato de criação, e não como atitude passiva ou olhar conformado. A experiência pedagógica com as práticas corporais gera traduções, ressignificações e negociações culturais. Os estudantes são incitados a falar sobre, mover-se a partir de, construir e experimentar, bem como acessar e analisar referências externas, narrativas, posicionamentos e conhecimentos que divirjam do repertório inicial, mas que conduzam a uma certa intimidade com o diferente (NEIRA, 2009).

Uma vez que a produção científica disponível sobre o currículo cultural afirma literalmente que se trata de uma proposta "a favor das diferenças", elegemos como objetivo do presente artigo provocar uma certa tensão nos seus princípios e procedimentos didáticos mediante o confronto com a noção deleuziana de diferença pura.

\footnotetext{
${ }^{1}$ A título de ilustração, vale mencionar que uma das obras que abordam o assunto tem por título Educação Física cultural: por uma pedagogia da(s) diferença(s).
}

Práxis Educativa, Ponta Grossa, v. 12, n. 2, p. 464-480, maio/ago. 2017 Disponível em: <http://www.revistas2.uepg.br/index.php/praxiseducativa $>$ 


\section{A diferença em Deleuze}

A temática da diferença é central na filosofia de Deleuze. Na visão do autor, a diferença é o elemento primordial do pensamento que, submetido aos limites da representação, é apenas reconhecimento e não ação. O termo representação indica a imagem e/ou a ideia de algum objeto conhecido. $\mathrm{O}$ uso do termo deve-se à noção de conhecimento como semelhança do objeto. O problema da representação surge, para Deleuze, quando identifica na representação clássica a busca pela representação do real, ou seja, vê na representação clássica uma tentativa de identificação, sendo o âmbito da identidade o da representação (MATHIAS, 2006).

A representação não apreende o que há de diferente em cada um de nós, o que há de singular. Porém, se olharmos para a história da filosofia dos gregos aos iluministas, veremos que sua grande promessa foi atrelar ao pensamento a função de reconhecimento, de representar o diferente seja pela via da exclusão, seja pela via da dominação, sempre buscando transformá-lo na identidade (AGUIAR, 1999).

Schöpke (2012) assevera que submeter sumariamente a diferença aos princípios da identidade e da semelhança (na representação) é selecionar aquilo que nela deverá ou não ser reconhecido pela razão. Dito de outra forma, o pensamento é apenas 're-conhecimento' quando está submetido e regulado pelos princípios da representação, ou seja, um simples processo de recognição. É exatamente como juíza de valor que a razão irá condenar tudo aquilo que lhe pareça um tanto quanto descentrado, desregrado, isto é, tudo aquilo que não se encaixa em um modelo 'prefixado'. Por essa razão que a diferença lhe escapa à compreensão, afinal, a diferença ameaça o equilíbrio da razão, que opera fundamentalmente com às relações de identidade e semelhança.

O grande objetivo de Deleuze é 'libertar' a diferença das antigas malhas da representação - que tende a transformá-la em um puro conceito do entendimento, uma forma vazia, sem qualquer vínculo com as suas múltiplas manifestações. Na verdade, a diferença submetida às regras da identidade e da semelhança - torna-se passível de ser 'estabelecida' porque obedece aos critérios rígidos do raciocínio lógico e representativo. Mas é aqui precisamente que, segundo Deleuze, a diferença perde realmente a sua natureza anárquica e subversiva (SCHÖPKE, 2012, p. 22, grifo da autora).

Para Deleuze (2006), quando a diferença é subordinada pelo sujeito pensante à identidade do conceito, o que desaparece é a diferença no pensamento, ou seja, a diferença de pensar com o pensamento. Restaurar a diferença no pensamento é desfazer este primeiro nó que consiste em representar a diferença sob a identidade do conceito e do sujeito pensante. "Na realidade, enquanto se inscreve a diferença no conceito em geral, não se tem nenhuma ideia singular da diferença, permanecendo-se apenas no elemento de uma diferença já mediatizada pela representação" (DELEUZE, 2006, p. 54).

O pensamento como afirmação da diferença, como afirmação de nossa própria diferença, é fazer do pensamento um modo de existência, uma máquina de guerra, cujo maior desafio é permanecer livre dos modelos de representação. A partir daí, Deleuze apresenta a ideia de diferença pura, a qual designa uma instância ontológica ${ }^{2}$, não podendo ser confundida com diferença empírica que se encontra nos corpos, e que é apenas uma forma (menor) da diferença. Foi preciso inventar um conceito que libertasse a diferença das regras limitadoras da representação, de sua subordinação à identidade, já que a representação nos fornece uma imagem menor da diferença. Era preciso dar à diferença uma 'voz' própria. Assim, a diferença pura escapa

\footnotetext{
2 O uso do termo se deve ao fato de que a diferença pura é a própria expressão do “ser”. (SCHÖPKE, 2012, p. 143).
} 
completamente à compreensão da razão, constituindo-se em uma ameaça ao seu perfeito equilíbrio (SCHÖPKE, 2012).

Para Deleuze, diferença pura é o objeto, por excelência, do pensamento. Se tomarmos o pensamento como potência criadora, seu objeto será a própria diferença, na sua mais pura 'ontologia'. Pensar o pensamento nos moldes da representação clássica é deixar escapar, exatamente, o que ele tem de original e singular (SCHÖPKE, 2012).

É preciso que a diferença se torne a última unidade, que ela remeta a outras diferenças que nunca a identificam, mas a diferenciam. É preciso que cada termo de uma série seja colocado numa relação variável com outros termos e constitua outras séries carentes de centro e de convergência. Cada ser deve ver sua própria identidade tragada pela diferença, cada uma sendo só uma diferença entre as diferenças. É preciso mostrar a diferença diferindo (DELEUZE, 2006).

Neste sentido, 'fugindo' de uma representação do termo diferença nos moldes do pensamento clássico, Deleuze afirmará que é no mundo dos simulacros que a diferença pura se constitui. O simulacro é a instância que compreende uma diferença em si, como duas séries divergentes (pelo menos) sobre as quais ela atua, toda semelhança tendo sido abolida sem que se possa, por conseguinte, indicar a existência de um original e de uma cópia (DELEUZE, 2006).

\begin{abstract}
A distinção modelo-cópia existe apenas para fundar e aplicar a distinção cópiasimulacro, pois as cópias são justificadas, salvas, selecionadas em nome da identidade do modelo e graças a sua semelhança interior com este modelo ideal. A noção de modelo não intervém para opor-se ao mundo das imagens em seu conjunto, mas para selecionar as boas imagens, aquelas que se assemelham do interior, os ícones, e para eliminar as más, os simulacros (DELEUZE, 2006, p. 184-185).
\end{abstract}

De acordo com Williams (2013), o simulacro é um signo da diferença ao invés de identidade. Resiste à representação e convida a repeti-la de novas e diferentes maneiras. Para Deleuze, os signos são múltiplas estruturas móveis de relações, ao invés de relações binárias. Sentido não é significado; é ruptura de identidade em significado e conhecimento através da sensação.

Sensações, intensidades e mudanças em estruturas fazem de cada um de 'nós' um indivíduo, e não uma pessoa individual do ser humano, ou sujeito. Cada indivíduo é o todo do mundo sob uma perspectiva singular, ao invés de um sub-ramo do grupo dos seres humanos ou pessoas. Sensações são sentimentos que vão além de rígidas percepções em comum. Antes, são relações individuais com eventos e que não podem ser diretamente relacionadas com outrem (WILLIAMS, 2013, p. 105).

$\mathrm{Na}$ ótica deleuziana esta marca individual não é uma representação e mesmice em escala menor, o que o conceito de simulacro tenta fazer: dizer que um signo não é uma relação de identidades, mas uma intensa sensação individual associada a um movimento dentro de todas as identidades atuais e com variações dentro de todas as estruturas virtuais ou ideais. O signo deve ser um simulacro (WILLIAMS, 2013).

Partindo deste pressuposto, Deleuze defende que os signos não são 'signos para' ou 'signos de' algo externo a um sistema de signos. Significantes não são primordialmente significantes de um significado mais importante. $O$ significado não é primordialmente um significado a ser remetido a uma cadeia de significados que levem a verdades últimas. Antes, há somente cópias e signos, livres de qualquer referência externa a objetos ou significados últimos. Tais cópias são simulacros, ou seja, variações de outros simulacros ou diferenças. Não há nenhuma origem, apenas uma cadeia externa de simulacros interconectados. Nada existe fora de tais cadeias. Isto significa que tudo depende de sua repetição, não tendo nenhuma realidade independente externa

Práxis Educativa, Ponta Grossa, v. 12, n. 2, p. 464-480, maio/ago. 2017 Disponível em: <http://www.revistas2.uepg.br/index.php/praxiseducativa> 
a essa repetição. Tudo existe apenas em retorno (o mesmo nunca retorna, apenas a diferença retorna), cópia de uma infinidade de cópias que não permitem nenhum original (WILLIAMS, 2013).

\begin{abstract}
Por isso, a diferença pura é o acontecimento maior do ser, presente no seu cerne. O ser se diz da diferença. Ela é objeto do pensamento e não da representação. Toda representação é afirmação da identidade e anulação da diferença. O ser somente existe enquanto diferença que é, e a diferença é um desdobramento do ser, que é devir e simulacro, que não se representa, por isso, sem semelhança, identidade e modelo. Neste sentido, o sujeito não é uma unidade-identidade. Deleuze substitui a lógica do ser pela lógica da conjunção; substitui o é pelo $e$ da conjunção que relaciona a identidade pela multiplicidade (DOMENÈCH, 2001 apud MATHIAS, 2006, p. 46, grifo do autor).
\end{abstract}

Assim, a diferença está no cerne do próprio ser, como a sua manifestação mais profunda. $\mathrm{O}$ ser, na verdade, se diz da diferença. Ele não é 'a' diferença em si, mas no sentido de um ser unívoco que se diz da diferença. Ressaltamos que, para Deleuze, a univocidade (unívoco) não significa que só há um único e mesmo ser para todas as coisas. Os seres são múltiplos e diferentes, produzidos por uma síntese disjuntiva, eles próprios disjuntos e divergentes. Em outras palavras, univocidade significa que todos os seres se dizem de uma mesma maneira e num único sentido. Uma só 'voz' para todos os seres. E uma só voz que diz não à identidade enquanto afirma a diferença e o devir. Ser unívoco significa multiplicidade e diferença e não identidade plena. Este é um mundo de simulacros e a relação essencial é entre o 'diferente' e o 'diferente' e não entre um modelo e as suas cópias, entre um idêntico e um semelhante (SCHÖPKE, 2012).

A partir destes argumentos podemos dizer que a diferença não é identidade, não está na semelhança e no já dado, mas sim, no que está por vir, no eterno retorno, na repetição. A diferença pura, como diz Deleuze, destrói o sonho das identidades plenas. Ela não é da esfera do sensível, e sim o ser do sensível. Ela não se representa na e pela identidade (MATHIAS, 2006).

É preciso que a diferença seja em si mesma articulação e ligação, que ela relacione o diferente ao diferente sem qualquer mediação pelo idêntico, pelo semelhante, pelo análogo ou pelo oposto. É preciso uma diferenciação da diferença, um em si como um diferenciador, um Sich-unterscheidende, pelo qual o diferente é ao mesmo tempo reunido, em vez de ser representado sob a condição de uma semelhança, de uma identidade, de uma analogia, de uma oposição prévias (DELEUZE, 2006, p. 172, grifo do autor).

Portanto, a diferença está no âmago do próprio ser. O ser não se pode dizer de outra maneira, uma vez que existir é já diferenciar-se. A diferença é um desdobramento do próprio ser, onde o ser não se apresenta, não se efetua fora dessas relações diferenciais. Ele emerge do caos como uma virtualidade que produz a diferença. Falar do ser é falar de todas as diferenças que o expressam (SCHÖPKE, 2012).

Em vez da identidade, que tenta reduzir a diversidade a um elemento comum, Deleuze prefere a diferença em si, a variação, a multiplicação, a disseminação e a proliferação. Em outras palavras, a diferença é pensada não como uma característica geral a serviço da generalidade do conceito, mas sim como puro acontecimento. Em vez do uno, do todo, da origem, valoriza a multiplicidade, a diferenciação, a repetição e a improvisação. Isso porque a diferença em Deleuze não é da ordem da representação; nãoo é produto nem tampouco resultado, não se refere ao diferente; não é relação; não é predicativa e nem propositiva, nunca é diferença entre dois indivíduos. Deleuze afirma a diferença em si: 'a diferença interna à própria coisa', o 'diferenciar-se em si da coisa' (PARAÍSO, 2010).

Conceber a identidade enquanto rasura, como ato de produção, estando esta intrinsecamente atrelada à diferença como apresentada anteriormente, contribui para a 
valorização das diferenças culturais na busca de uma maior equidade na sociedade, no entanto, tensionar estes conceitos frente ao pensamento da diferença pura potencializa pensarmos diferentes maneiras de estar no mundo e de conceber outrem, concebendo-se em si mesmo, desestruturando culturas e possibilitando novas realidades. Pensar os modos de ser/estar no mundo tendo a diferença pura como alavanca só pode contribuir para desestabilizarmos verdades e compreendermos as diferenças culturais como processos provisórios de um mundo em constante mudança, onde as virtualidades se atualizam regulando e desregulando os processos identificatórios.

\section{A diferença nos princípios e procedimentos didáticos do currículo cultural da Educação Física}

As revisões sistemáticas da produção científica sobre as teorias curriculares da Educação Física realizadas por Rocha et al. (2015) e Martins (2016) identificaram a concentração de trabalhos sobre a perspectiva cultural do componente no Grupo de Pesquisas em Educação Física escolar da Faculdade de Educação da Universidade de São Paulo. A consulta ao portal eletrônico ${ }^{3}$ desse coletivo de pesquisadores permite constatar diversos livros, capítulos de livro, artigos, dissertações, teses, relatos de prática e relatórios de pesquisa sobre o assunto. A influência dessa produção alcançou propostas curriculares oficiais ${ }^{4}$ e alguns desses trabalhos têm constituído a bibliografia de diversos concursos públicos para a contratação de professores.

O contato com essa produção permitiu-nos identificar a recorrência ${ }^{5}$ de alguns princípios e procedimentos didáticos que buscam dar 'forma' ao currículo cultural. No entanto, vale ressaltar que não devem ser tomados como algo estanque, sequencial, mas sim como hastes de rizomas ${ }^{6}$. Apesar de termos realizado a análise separadamente, vale ressaltar que no currículo cultural as atividades de ensino se diversificam, hibridizam, entrecruzam e multiplicam, adquirindo uma conotação "artística" (CORAZZA, 2007).

Um primeiro princípio a ser considerado é reconhecer a cultura corporal da comunidade, o que implica em considerar os modos de significação específicos dos estudantes acessados no seu cotidiano. Trata-se de desenvolver uma prática pedagógica em sintonia com a cultura de chegada, frequentemente, desvalorizada pela cultura dominante (NEIRA, 2011).

A consideração do patrimônio corporal da comunidade potencializa o trato com a diferença na escola, pois abre espaço para a negociação cultural envolvendo o acadêmico, o popular e o midiático, entre outros. Surge desse encontro a oportunidade de compreender e intercambiar os diferentes sentidos atribuídos às brincadeiras, danças, lutas, esportes e ginásticas. O currículo cultural de Educação Física rejeita qualquer tipo de marcação e perpetuação de um modelo único e determinado, pois é lugar de estudo das diferentes manifestações da cultura corporal. Afinal, "quando o sujeito entra em contato com as práticas corporais de outros grupos, vivencia uma relação interpretativa movida pela busca de compreensão de seu significado" (NEIRA, 2009, p. 87).

\footnotetext{
$3<$ http://www.gpef.fe.usp.br>.

${ }^{4}$ O estudo de Gramorelli (2014) identificou a presença da perspectiva cultural em currículos estaduais. Além deles, as propostas dos municípios de São Paulo (2007 e 2016), Rio de Janeiro, Itatiba (SP), Cubatão (SP) e as redes privadas Marista e SESI-SP apoiaram-se nos mesmos referenciais.

${ }^{5}$ Para dar fluidez à leitura, referenciamos apenas a obra em que o princípio ou orientação didática são mencionados pela primeira vez.

${ }^{6}$ A acepção do termo será elucidada nas páginas abaixo.
}

Práxis Educativa, Ponta Grossa, v. 12, n. 2, p. 464-480, maio/ago. 2017 Disponível em: <http://www.revistas2.uepg.br/index.php/praxiseducativa $>$ 
Entendemos que um olhar a partir da diferença nas aulas de Educação Física, ao valorizar as práticas corporais dos grupos que foram e são subjugados e as vozes dos seus sujeitos ${ }^{7}$, legitima suas formas de expressão, rompe com a ilusória homogeneidade presente no universo escolar, abre espaço para a produção da diferença e contribui para uma sociedade mais solidária.

[...] para ver a diferença proliferar, então, é preciso pensar em multiplicidades: afinal, se um código de currículo funciona é porque, uma professora que é uma das codificadoras de um currículo, faz parte de uma multidão, de uma matilha curriculante. Para operar por multiplicidade, um currículo é despojado de qualquer significação, já que não se forma a não ser no processo de anulação dos referentes. Isso porque a energia provém do processo de desmontagem de todos os modelos de currículos já incorporados (PARAÍSO, 2005, p. 7).

O princípio da justiça curricular se compromete com a tematização de práticas corporais pertencentes aos vários grupos culturais que coabitam a sociedade com o objetivo de promover a justiça social no interior do currículo, ou seja, proporcionar a aproximação e o diálogo com os saberes e visões de mundo até então alijados da experiência escolar (NEIRA; NUNES, 2009).

O trabalho pedagógico inspirado nesse princípio realiza a ação contra-hegemônica de desestabilizar o privilégio das práticas corporais elitizadas, abrindo fendas para a penetração de saberes oriundos de outros setores da malha social. Tal princípio impede a perpetuação da perspectiva monocultural, ou seja, a premência de uma só visão de mundo.

Outro princípio enunciado é a descolonização do currículo. O qual procura desestabilizar o privilégio dos conhecimentos e discursos produzidos por determinados grupos em detrimento de outros, no sentido de minimizar a desqualificação impetrada às temáticas pertencentes aos grupos minoritários, procurando abordá-las no currículo (NEIRA, 2011).

Já a ancoragem social dos conhecimentos busca estabelecer conexões entre os diferentes discursos históricos, políticos e sociológicos que envolvem as práticas corporais. Tem por objetivo reconhecer a origem e os processos de transformação que marcaram e marcam as manifestações da cultura corporal (NEIRA; NUNES, 2009).

Por fim, o currículo cultural também tem como princípio evitar o daltonismo cultural, o qual, pretende combater o não reconhecimento da heterogeneidade cultural presente na própria comunidade escolar, distorção que acaba por atribuir uma mesma identidade aos estudantes e atribuir semelhanças a seus saberes e concepções (NEIRA; NUNES, 2009). Concebendo todos/as como diferentes, este princípio estabelece um olhar singular para cada qual. Invertendo a lógica da identidade, da homogeneização no currículo e focando o trabalho a partir da diferença, atua em sintonia com uma educação mais justa e equitativa.

A luta dos grupos subordinados que clamam pelo reconhecimento dos seus direitos é tema central na composição de espaços que legitimem as diferentes culturas. Entendendo a escola como um desses ambientes, abordar a questão da diferença é fundamental para a valorização e solidarização com outrem, porém, em tempos de recrudescimento de valores conservadores, artistar um currículo de Educação Física sob a cunha da diferença não é uma tarefa de pouca monta. Em forma de alento, Silva (2012, p. 101) adverte: "educar significa introduzir a cunha da diferença em um mundo que sem ela se limitaria a reproduzir o igual e o idêntico, um mundo parado, um mundo morto. É nessa possibilidade de abertura para um outro mundo que podemos pensar na pedagogia como diferença."

\footnotetext{
7 A partir do referencial teórico utilizado vale ressaltar que se trata de um sujeito descentrado, subjetivado por uma rede de agenciamentos, ou seja, o sujeito como apenas uma das singularidades colocada no plano de imanência em que nos realizamos.
}

Práxis Educativa, Ponta Grossa, v. 12, n. 2, p. 464-480, maio/ago. 2017 Disponível em: <http://www.revistas2.uepg.br/index.php/praxiseducativa $>$ 
[...] não se trata de promover a celebração da identidade e da diferença, um dos pontos fortes de críticas dirigidas aos argumentos 'pós' por um suposto relativismo ou vale tudo que poderia colocar enormes problemas para a agência e ação política. Trata-se de problematizá-las, vê-las como uma questão de produção, e de estar atentos aos mecanismos envolvidos nessa produção. Trata-se de questionar nossos próprios sistemas de diferença em seus significados, reconhecendo que podem ser considerados igualmente estranhos ou absurdos sob diferentes pontos de vista (SILVA, 2006, p. 0809).

Como se pode depreender dos princípios acima, o currículo cultural da Educação Física busca identificar os discursos que perpassam as práticas corporais presentes na sociedade, como são produzidas, quais relações de poder estão presentes, quais grupos definem os significados, quais interesses permeiam seus discursos. Essa perspectiva curricular potencializa a produção de linhas de fuga como apontado por Deleuze e Guattari (1977), as quais desfazem todas as formas pré-concebidas de currículo em proveito de uma matéria não formada, de fluxos desterritorializados, de signos assignificantes.

Para além dos princípios mencionados, a análise da produção sobre o currículo cultural da Educação Física também identificou procedimentos didáticos específicos. A prática pedagógica se inicia com o mapeamento. Mapear significa identificar o patrimônio cultural corporal disponível na comunidade, ou seja, o conjunto de práticas corporais, significados e conhecimentos que abarcam as brincadeiras, danças, lutas, esportes e ginásticas com os quais os estudantes já interagiram (NEIRA; NUNES, 2008).

O currículo cultural valoriza o estudo de práticas corporais que possuem lastro social, sentido e significado para os grupos que delas participam. Os grupos vistos como diferentes também têm suas formas de manifestação elencadas como objetos de estudo e, consequentemente, suas características e peculiariedades se farão representar, abrindo possibilidades para que suas vozes, por vezes silenciadas, ecoem e influenciem a constituição da subjetividade dos estudantes e professores.

A tematização de uma prática corporal pode ocorrer de maneira articulada aos saberes comumente abordados pelas demais disciplinas, pelo desenvolvimento de projetos em comum ou, ainda, como algo central de um projeto específico da Educação Física. Tematizar significa destrinchar, analisar, abordar inúmeros conteúdos que (advindos de uma rigorosa etnografia da prática corporal em foco), permitirão melhor compreender a sua ocorrência social, assim como os que a produziram e/ou reproduzem (NEIRA; NUNES, 2009).

É por meio da tematização das práticas corporais que docentes e estudantes acessam diferentes discursos, representações e produzem novos significados com relação à cultura corporal. Assim, entendemos que se potencializa de maneira mais equânime o trabalho na escola e na Educação Física, encorajando os sujeitos a pensar, discutir e dialogar sobre seus conhecimentos e representações acerca dos artefatos da cultura corporal. A intenção é alertar e questionar a preferência de certas práticas corporais em detrimento de outras, além dos significados que lhes são atribuídos e também aos seus praticantes, auxiliando na compreensão da lógica que estabelece tais relações.

Outra orientação didática importante no currículo cultural é a realização, tanto por parte dos docentes quanto dos estudantes, de uma etnografia da prática corporal. Enquanto atividade de ensino, a etnografia significa aproximar-se das práticas corporais e compreender como operam os mecanismos de dominação e de resistência, de opressão e de contestação que subjazem ao papel

Práxis Educativa, Ponta Grossa, v. 12, n. 2, p. 464-480, maio/ago. 2017 Disponível em: <http://www.revistas2.uepg.br/index.php/praxiseducativa > 
e à atuação de seus praticantes. Durante o processo etnográfico, o docente juntamente com os estudantes, descobre os códigos linguísticos, signos culturais, ações movidas pelo poder e ideologias coladas nas brincadeiras, danças, lutas, ginásticas e esportes (NEIRA, 2011).

A partir do que se enuncia, das representações que se atualizam no contexto da aula, dos discursos que circulam sobre a prática corporal tema de estudo, tem-se um campo fértil para a realização da problematização. O objetivo é fomentar análises cada vez mais profundas e ampliadas acerca das condições assimétricas de poder cristalizadas nas relações de gênero, etnia, geração, entre outras, que imprimem suas marcas na manifestação em estudo (NEIRA; NUNES, 2009).

Problematizar significa exercer uma análise crítica dos modos como às práticas corporais são realizadas e discursadas. Em outras palavras, é o desafio que o docente lança aos estudantes para que pensem sobre os aspectos que não haviam sido percebidos de maneira crítica, apesar de constituírem as situações vividas. Assim, docentes e estudantes, ao problematizarem as representações postas em circulação, fomentam análises cada vez mais profundas e acessam diferentes saberes, possibilitando a construção de sínteses coletivas.

O mapeamento, a tematização, a etnografia das práticas corporais e a problematização nos permitem pensar o currículo cultural de Educação Física a partir do conceito de diferença pura de Deleuze, quando retiram o foco da identidade como representação (no sentido da recognição) e rompem com a ideia de reunir a semelhança, classificando-a em uma identidade. Afinal, "se a reunião é o critério da generalidade e da identidade, o acontecimento é o critério da diferença. A diferença é o que vem primeiro; é o motor da criação; é a possibilidade de no meio, no espaço-entre começar a brotar hastes de rizoma" (PARAÍSO, 2005, p. 04-05).

Deleuze e Guattari (1995) salientam que pensar as coisas a partir do pensamento rizomático é opor-se ao pensamento arbóreo, ou seja, o pensamento que se dá por meio da filiação, um pensamento enraizado. Diferentemente, o rizoma conecta qualquer ponto com outro ponto e cada um dos seus traços não remete a traços da mesma natureza. Ao invés de uma estrutura que se define por um conjunto de pontos e por correlações binárias entre eles, o rizoma é feito somente de linhas. Refere-se a um mapa que deve ser produzido, construído, sendo sempre desmontável, conectável, reversível, modificável, com múltiplas entradas e saídas, com linhas de fuga.

[...] um rizoma não começa nem conclui, ele se encontra sempre no meio, entre as coisas, inter-ser, intermezzo. A árvore é filiação, mas o rizoma é aliança, unicamente aliança. A árvore impõe o verbo 'ser', mas o rizoma tem como tecido a conjunção 'e... e... e...’ [...] Entre as coisas não designa uma correlação localizável que vai de uma para outra e reciprocamente, mas uma direção perpendicular, um movimento transversal que as carrega uma $e$ outra, riacho sem início nem fim, que rói suas duas margens e adquire velocidade no meio (DELEUZE; GUATTARI, 1995, p. 36, grifo dos autores).

Conceber o trabalho pedagógico na perspectiva rizomática requer a compreensão de que existem diversas formas de conhecer que dialogam entre si em contextos histórico-sociais específicos, estabelecendo múltiplas conexões entre os saberes científicos, populares, míticos e artísticos.

Tomando de empréstimo a imagem criada por Deleuze e Guattari (2000), é possível afirmar que na proposta cultural da Educação Física o conhecimento é tecido rizomaticamente, em oposição à maneira segmentada de se conceber a realidade, bem como o modo positivista de se construir os conceitos. Dito de outra forma, a verticalidade das árvores que erigiram os conhecimentos 'verdadeiros' das propostas convencionais da Educação Física, na perspectiva cultural, dá lugar à horizontalidade dos rizomas, onde a produção do conhecimento é sempre provisória, múltipla, em devir e baseada na diferença (SANTOS; NEIRA, 2016, p. 158).

Práxis Educativa, Ponta Grossa, v. 12, n. 2, p. 464-480, maio/ago. 2017 Disponível em: <http://www.revistas2.uepg.br/index.php/praxiseducativa > 
Ressignificar é outra orientação didática que caracteriza o currículo cultural. Implica atribuir novos sentidos e significados a uma prática corporal produzida em outro contexto com base na própria experiência cultural. Assim, diante das condições que diferenciam a prática social da manifestação no seu locus original e a realidade da escola (número de estudantes, espaço, tempo, material disponível etc.), o docente estimula a turma a elaborar novas formas de vivenciá-la, com a intenção de facilitar a compreensão da plasticidade da cultura e do processo de transformação vivido pelos diferentes produtos culturais (NEIRA; NUNES, 2008).

A partir do processo de ressignificação, o currículo cultural da Educação Física analisa as razões que impulsionaram determinadas modificações nas práticas corporais, assim como os acontecimentos que geraram a sua transformação. Os fatores relacionados às questões de etnia, classe social, cultura, gênero, entre outros, são obrigatoriamente discutidos e, como tarefa didática, tanto o docente quanto os estudantes exercitam coletivamente a reconstrução da brincadeira, dança, luta, ginástica ou esporte, analisando-os e adaptando-os ao contexto sociocultural em que se encontram.

Todavia, não basta somente vivenciar e reconstruir as práticas corporais estudadas, ao longo do currículo também é fundamental que os estudantes aprofundem os conhecimentos e ampliem as fontes de significação (NEIRA; NUNES, 2009). O aprofundamento e a ampliação são procedimentos didáticos que tipificam o currículo cultural. Aprofundar significa conhecer melhor a manifestação corporal, procurando desvelar aspectos que lhe pertencem, mas que não apareceram nas primeiras leituras e significações realizadas. Aspectos destacados pelos estudantes ou pelo docente durante o aprofundamento fomentam novas vertentes de análises, vivências e pesquisas.

Ampliar, por sua vez, significa recorrer a outros discursos e fontes de informações que possam oferecer olhares diferentes e contraditórios às representações e discursos inicialmente acessados. A ampliação prioriza perspectivas de análise raramente disponíveis aos estudantes, acessadas por meio de entrevistas com pessoas cuja história de vida foi marcada pela prática corporal objeto de estudo, leitura de textos argumentativos, assistência a documentários, comparação entre diferentes pontos de vista etc.

Por fim, temos a avaliação e registro, procedimentos didáticos fundamentais à concretização do currículo cultural, afinal, é a partir dos registros feitos tanto pelo docente quanto pelos estudantes que novos horizontes são produzidos, reorientando as atividades de ensino vindouras. Observar, registrar e analisar o cotidiano das aulas possibilita a reunião de informações necessárias para a avaliação do trabalho pedagógico (NEIRA; NUNES, 2008).

O registro documenta o processo, viabilizando a avaliação, replanejamento e reorientando as atividades de ensino. É a avaliação que permite identificar e analisar as significações dos estudantes e organizar a síntese, a fim de reconhecer o que foi dito e feito. Através dela torna-se possível dialogar com o entorno e desconstruir representações pejorativas acerca das diferenças.

Como evidenciou Bonetto (2016), os professores que colocam em ação o currículo cultural operam a partir dos enunciados pedagógicos dos princípios curriculares e dos procedimentos didáticos. O autor estabelece uma relação com as linhas de segmentaridade ${ }^{8}$ propostas por Deleuze e vê nos princípios curriculares do currículo cultural uma forte aproximação com as linhas moleculares (ou flexíveis) e, nos procedimentos didáticos, uma evidente relação com as linhas molares (ou duras) e passando entre estas, as linhas de fuga.

${ }^{8}$ Deleuze concebe as linhas de segmentaridade enquanto canais que conectam segmentos.

Práxis Educativa, Ponta Grossa, v. 12, n. 2, p. 464-480, maio/ago. 2017 Disponível em: <http://www.revistas2.uepg.br/index.php/praxiseducativa> 
Estas duas linhas não param de se cruzarem, de interferirem, de reagir uma com a outra, e assim, não deixam de introduzir cada uma na outra uma corrente de maleabilidade ou mesmo um ponto de rigidez. Entretanto, estas três linhas não param de se cruzar e misturar, elas não só coexistem, mas se transformam, passam uma na outra. Neste sentido, as linhas se cruzam constantemente, se superpõem por um instante, se seguem por um certo tempo. E, então, a criança faz algo que não pertence mais a nenhuma das duas linhas (molar e molecular), reencontra algo que havia perdido, salta, agita, emite diversas linhas. Em suma, uma linha de fuga, já complexa, com suas singularidades; mas também uma linha molar ou costumeira com seus segmentos; e entre as duas (?), uma linha molecular, com seus quanta que a fazem pender para um lado ou para outro (DELEUZE; GUATTARI, 2012, p. 84).

Para Deleuze e Guattari (2012), somos atravessados por linhas, meridianos, fusos que não seguem a mesma direção ou ritmo e não têm a mesma natureza. Podemos nos interessar mais por uma dessas linhas do que por outras. Algumas nos são impostas de fora, outras nascem por acaso, de um nada, nunca sabemos por quê. Já outras, devem ser inventadas, traçadas, sem nenhum modelo nem acaso. Assim, devemos inventar nossas linhas de fuga se formos capazes disso e só podemos inventá-las traçando-as, efetivamente, na vida.

Pensar uma pedagogia da diferença no currículo cultural da Educação Física exige, no terreno empírico, um olhar atento à diferença cultural e, no âmbito do pensamento, a criação de novas maneiras de se relacionar com o trato pedagógico das práticas corporais, rompendo com a lógica instituída na escola, ou seja, a fixação de identidades através da aprendizagem baseada na reprodução. A ruptura desse processo só pode ocorrer no movimento entre linhas molares, moleculares e linhas de fuga.

É na relação, no envolvimento das linhas segmentárias do currículo cultural que vemos a possibilidade de o professor potencializar atos de criação. É nas experiências vivenciadas pelos estudantes que pequenos instantes se farão articuladores de novas maneiras de pensar as manifestações da cultura corporal e os seus praticantes e, assim, radicalizar o que pode um corpo, uma expressão, um conhecimento da cultura corporal, um momento criativo, um acontecimento ${ }^{9}$, onde a diferença pura irrompe e faz surgir novas possibilidades frente ao estudo das práticas corporais na escola.

É a partir do jogo da diferença estabelecido entre as linhas de segmentaridade que se vislumbra um sentir, um pensar e um descrever a diferença pura. Por mais que esteja atrelada à noção de diferença cultural, os princípios curriculares e procedimentos didáticos criam possibilidades de escapar, de pensar o currículo da Educação Física para além do binômio identidade versus diferença, caminhando na direção de uma diferença por ela mesma, de valorização da diferença em si.

\section{Considerações transitórias}

A partir do exposto, podemos pressupor que uma das características do currículo cultural passa a ser o que Gallo (2008) inspirado na obra Kafka: Por uma literatura menor de Gilles Deleuze e Félix Guattari - denominou de 'educação menor', ou seja, realizar uma prática pedagógica liberta das amarras presentes nas grandes teorias e narrativas que sempre posicionaram a escola como lugar da educação dos grandes mapas, grandes projetos, produzida na macropolítica, nos gabinetes e expressa nos documentos. Essa educação maior procura construir-se como uma

\footnotetext{
${ }^{9}$ Suscitar acontecimentos na educação é abrir-se para o que acontece, seja na sala de aula ou em outros espaços escolares. Ir além do planejado, dos objetivos predefinidos. Atentar mais para a trajetória do que para o ponto de chegada (GALLO, 2015).
}

Práxis Educativa, Ponta Grossa, v. 12, n. 2, p. 464-480, maio/ago. 2017 Disponível em: <http://www.revistas2.uepg.br/index.php/praxiseducativa> 
máquina de controle, uma máquina de subjetivação, de produção de indivíduos em série. Cada estudante é, nada mais, nada menos, do que uma pequena peça de uma engrenagem maior. Pensar desta maneira acaba por pressupor que existe uma correspondência direta entre ensinar e aprender.

No sentido contrário, aprender está para alguém que procura, mesmo que não saiba o que, assim como para alguém que encontra, mesmo que seja algo que não tenha sido procurado (GALLO, 2002). A aprendizagem é algo que escapa, que foge ao controle, a aprendizagem é feita de multiplicidades. Podemos planejar e executar tudo como o planejado, tomando todos os cuidados possíveis e imagináveis; mas sempre algo poderá fugir do controle, escapar por entre as bordas, trazendo à luz um resultado inimaginável. Agimos sem nunca saber quais serão os resultados de nossas ações. Uma atividade de ensino pode funcionar muito bem em nossas cabeças, mas produzir situações e resultados completamente distintos nos estudantes. Pode até haver métodos para ensinar, mas não há métodos para aprender. O método é uma máquina de controle, a aprendizagem está para além de qualquer controle; a aprendizagem escapa sempre (GALLO, 2008).

Toda educação é um ato político, na educação menor isso é mais evidente por tratar-se de um empreendimento de revolta e resistência. A ramificação política da educação menor, ao agir no sentido de enfraquecer as diretrizes políticas da educação maior, abre espaço para que o docente exerça suas ações em um nível micropolítico, criando trincheiras a partir das quais se promove uma política do cotidiano, das relações direta entre os indivíduos, que por sua vez exercem efeitos sobre as macro relações sociais (GALLO, 2002).

[...] a educação menor é rizomática, segmentada, fragmentária, não está preocupada com a instauração de nenhuma falsa totalidade. Não interessa à educação menor criar modelos, propor caminhos, impor soluções. Não se trata de buscar a complexidade de uma suposta unidade perdida. Não se trata de buscar a integração dos saberes. Importa fazer rizoma. Viabilizar conexões e conexões; conexões sempre novas. Fazer rizoma com os alunos, viabilizar rizomas entre os alunos, fazer rizomas com projetos de outros professores. Manter os projetos abertos (GALLO, 2002, p. 175-176).

O docente, ao escolher sua atuação na escola, estará escolhendo para si e para todos com os quais trabalha. Na educação menor, não há espaço para políticas isoladas, pois toda a ação implica em muitos sujeitos. Toda singularização será, ao mesmo tempo, singularização coletiva (GALLO, 2002).

Se pudermos pensar o currículo cultural da Educação Física como uma educação menor, ou seja, uma Educação (Física) menor, teremos que considerar que tal possibilidade está condicionada à capacidade de não se render aos mecanismos de controle. Para que isso não ocorra, é preciso resistir. Resistir à cooptação, resistir a ser incorporado, manter acesa a chama da revolta, o orgulho da minoridade, apostar na possibilidade da diferença.

Tematizar as práticas corporais sem perder seu viés político, abrir espaço para diferentes leituras e significações, para o estudo das manifestações que historicamente não tiveram lugar no currículo escolar e romper com a lógica de uma Educação Física como simples prática de movimento corporal, são alguns dos desafios que o currículo cultural ousa enfrentar, sendo uma possibilidade dentre tantas outras.

Enquanto Educação (Física) menor, não está preocupada com a dicotomia entre teoria e prática, isso só faz sentido em uma Educação Física maior. Em uma Educação (Física) menor todas as atividades de ensino propostas são linhas de intensidade, linhas de fuga - não no sentido de fugir da realidade, mas sim da representação como recognição - ligadas à política, 
problematizando a todo momento os discursos e significações que circundam as práticas corporais, desmontando seus agenciamentos.

Ainda que potente para pensar a diferença pura nos seus entremeios, salientamos que um dos desafios do currículo cultural de Educação Física é pensar a diferença em si em primazia à identidade, ou seja, em seu estado mais puro (diferença pura) e não subordinada à identidade. A busca é fugir do pensamento como representação (recognição), onde a diferença é tida como um desvio, algo a ser 'consertado'. Pensando de outro modo, o estudo das práticas corporais na escola passa a ser entendido como texto, como uma singularidade, aberto aos mais diferentes encontros com os diversos conhecimentos e tipos de pensamento, passível de leituras, releituras e múltiplas significações.

Desse modo, ao colocar em ação o currículo cultural de Educação Física, o docente se metamorfoseia em um docente-artista/artista-docente ${ }^{10}$. Por meio das atividades de ensino, constrói junto aos estudantes novas produções acerca das práticas corporais e das pessoas que com elas se envolvem, dando espaço para as manifestações menores no sentido de uma educação menor, ou seja, práticas corporais desterritorializadas, que estão longe dos cânones estabelecidos por currículos homogeneizantes, abrindo assim, espaço para as diferenças.

Nas palavras de Neira (2014), uma Educação Física culturalmente orientada parte do princípio de que um bom ensino é aquele que considera o patrimônio da comunidade e abre espaço para a diversidade de etnias, classes sociais, religiões, gêneros e demais marcadores sociais que impregnam a cultura corporal das populações estudantis. $O$ currículo cultural não considera que as diferenças sejam impeditivos nem que os diferentes sejam vítimas a quem é preciso diagnosticar, dominar, controlar, regular e normalizar. Em uma pedagogia cultural, as diferenças funcionam como pontos de partida para a pratica pedagógica. O currículo cultural escuta o que os diferentes têm a dizer e presta atenção no repertório cultural corporal que os estudantes acessam.

Parafraseando Paraíso (2005), podemos afirmar que o currículo cultural de Educação Física tem potência para colocar em circulação outros modos de fazer, ou seja, permite aos docentes e estudantes partilhar, viajar sem mapas prévios, fazer outros traços, fugir, fazendo composições e conexões, inventar, aprender, caminhar por lugares insuspeitados, aumentando nossa potência de agir. Escapar das tentativas de captura, deslizar, fugir e criar um outro currículo, que sempre será único, inapreensível, singular.

Os docentes, ao desenvolverem uma Educação (Física) menor, tendo o currículo cultural como apoio, possibilitam um saber da experiência aos estudantes a partir das manifestações da cultura corporal que circulam no mundo. Conforme se observou nos princípios e procedimentos didáticos, os docentes engendram uma pedagogia da diferença, fazendo com que o currículo se mova e se contingencie a depender do contexto e dos agenciamentos realizados, possibilitando assim, um saber da experiência.

\footnotetext{
10 Docentes artistas/artistas docentes são tomados de devir-simulacros. Quando compõem, pintam, estudam, escrevem, pesquisam e ensinam têm apenas um objetivo, desencadear devires. Devires que são sempre moleculares (fluxos, intensidades), já que devir não é imitar algo, nem identificar-se com alguém ou promover relações formais de identidades. A partir da bagagem cultural que esses docentes-artistas possuem, do sujeito em que se transformaram, das funções educativas que aprenderam a exercer, devir-simulacro é extrair partículas disso tudo, que são as mais próximas daquilo que eles estão em vias de se tornarem, educadores, professores, pedagogos e artistas diferentes do que são (CORAZZA, 2007).
}

Práxis Educativa, Ponta Grossa, v. 12, n. 2, p. 464-480, maio/ago. 2017 Disponível em: <http://www.revistas2.uepg.br/index.php/praxiseducativa > 
[...] saber da experiência é um saber particular, subjetivo, relativo, contingente, pessoal. Se a experiência não é o que acontece, mas o que nos acontece, duas pessoas, ainda que enfrentem o mesmo acontecimento, não fazem a mesma experiência. $\mathrm{O}$ acontecimento é comum, mas a experiência é para cada qual sua, singular e de alguma maneira impossível de ser repetida. O saber da experiência é um saber que não pode separar-se do indivíduo concreto em quem encarna. Não está, como o conhecimento científico, fora de nós, mas somente tem sentido no modo como configura uma personalidade, um caráter, uma sensibilidade ou, em definitivo, uma forma humana singular de estar no mundo, que é por sua vez uma ética (um modo de conduzir-se) e uma estética (um estilo) (LARROSA, 2002, p. 27).

Praticar uma Educação (Física) menor é olhar para a experiência singular que o currículo proporciona, produzindo diferença, heterogeneidade e pluralidade no pensamento. Afinal, se em uma Educação Física maior a aula é repetível e previsível, na Educação (Física) menor a aula é uma experiência irrepetível, incerta, pois, como bem nos ensinou Larrosa (2002, p. 28), "a experiência não é o caminho até um objetivo previsto, até uma meta que se conhece de antemão, mas é uma abertura para o desconhecido, para o que não se pode antecipar nem 'pré-ver' nem 'pré-dizer"'.

\section{Referências}

AGUIAR, F. Com palmos medida: terra, trabalho e conflito na literatura brasileira. São Paulo: Boitempo Editorial, 1999.

BAUMAN, Z. Modernidade líquida. Rio de Janeiro: Zahar, 2003.

BONETTO, P. X. R. A “escrita-currículo” da perspectiva cultural de educação física: entre aproximações, diferenciações, laissez-faire e fórmula. 2016. 250 f. Dissertação (Mestrado em Educação) - Universidade de São Paulo, São Paulo, 2016.

CORAZZA, S. O que Deleuze quer da Educação? Revista Educação, São Paulo, v. 4, n. 6, p. 16-27, 2007.

DELEUZE, G. Diferença e repetição. Rio de Janeiro: Graal, 2006.

DELEUZE, G.; GUATTARI, F. Kafka: por uma literatura menor. Tradução de Júlio Castanõn Guimarães. Rio de Janeiro: Imago, 1977.

DELEUZE, G.; GUATTARI, F. Mil platôs - capitalismo e esquizofrenia. Rio de Janeiro: Editora 34, 1995. v. 1.

DELEUZE, G.; GUATTARI, F. Mil platôs - capitalismo e esquizofrenia. Rio de Janeiro: Editora 34, 2012. v. 3.

DOMENECH, M.; TIRADO, F.; GÓMEZ, L. A dobra: psicologia e subjetivação. In: SILVA, T. T. (Org.). Nunca fomos humanos: nos rastros do sujeito. Belo Horizonte: Autêntica, 2001. p. 111-136.

ESTEBAN, M. T. Avaliação: uma prática em busca de novos sentidos. Rio de Janeiro: DP\&A, 2003. 
GALLO, S. Em torno de uma educação menor. Educação \& Realidade, Porto Alegre, v. 27, n. 2, p. 169-178, jul./dez. 2002.

GALLO, S. Deleuze e a educação. Belo Horizonte: Autêntica, 2008.

GRAMORELLI, L. C.A cultura corporal nas propostas curriculares estaduais de Educação Física: novas paisagens para um novo tempo. 2014. 188 f. Tese (Doutorado em Educação) - Universidade de São Paulo, São Paulo, 2014.

HALL, S. A identidade cultural na pós-modernidade. Rio de Janeiro: DP\&A, 2011.

LARROSA, B. J. Notas sobre a experiência e o saber de experiência. Revista Brasileira de Educação, Rio de Janeiro, n. 19, p. 20-28, jan./abr. 2002. DOI: 10.1590/S141324782002000100003

LOPES, A. C.; MACEDO, E. Teorias de currículo. São Paulo: Cortez, 2011.

MARTINS, A. T. Educação Física culturalmente orientada e deficiência: uma experiência na Educação de Jovens e Adultos. Relatório de Pesquisa. São Paulo: FEUSP, 2016.

MATHIAS, J. R. A. Identidade e diferença: sentidos construção. 2006. 191 f. Tese (Doutorado em Comunicação) - Escola de Comunicação e Artes, Universidade de São Paulo, São Paulo, 2006.

NEIRA, M. G. Educação Física na perspectiva cultural: proposições a partir do debate em torno do currículo e da expansão do Ensino Fundamental. Horizontes, Itatiba, v. 27, n. 2, p. 7989, jul./dez. 2009.

NEIRA, M. G. A reflexão e a prática no ensino - Educação Física. São Paulo: Blucher, 2011.

NEIRA, M. G. Etnografando a prática do skate: elementos para o currículo da educação física. Revista Contemporânea de Educação, Rio de Janeiro, v. 9, n. 18, jul./dez. 2014. DOI: 10.20500/rce.v9i18.1861

NEIRA, M. G; NUNES, M. L. F. Pedagogia da cultura corporal: crítica e alternativa. São Paulo: Phorte, 2008.

NEIRA, M. G.; NUNES, M. L. F. Educação Física, currículo e cultura. São Paulo: Phorte, 2009.

NEIRA, M. G. Educação Física cultural: por uma pedagogia da(s) diferença(s). Curitiba: CRV, 2016.

PARAÍSO, M. A. Diferença em si no currículo. In: REUNIÃO ANUAL DA ASSOCIAÇÃO NACIONAL DE PÓS-GRADUAÇÃO E PESQUISA EM EDUCAÇÃO, 28., 2005, CaxambuMG. Anais... Caxambu-MG, 2005.

PARAÍSO, M. A. Diferença no currículo. Cadernos de Pesquisa, São Paulo, v. 40, n. 140, p. 587-604, maio/ago. 2010. DOI: 10.1590/s0100-15742010000200014 
ROCHA, M. A. B. et al. As teorias curriculares nas produções acerca da Educação Física escolar: uma revisão sistemática. Currículo Sem Fronteiras, v. 15, p. 178-194, 2015.

SANTOS, I. L.; NEIRA, M. G. A tematização no ensino da Educação Física. In: NEIRA, M. G. Educação Física cultural. São Paulo, Blucher, 2016. p. 149-165.

SCHÖPKE, R. Por uma filosofia da diferença: Gilles Deleuze, o pensador nômade. Rio de Janeiro: Contraponto, 2012.

SILVA, J. M. M. O currículo sob a cunha da diferença. In: REUNIÃO ANUAL DA ASSOCIAÇÃO NACIONAL DE PÓS-GRADUAÇÃO E PESQUISA EM EDUCAÇÃO, 29., 2006, Caxambu-MG. Anais... Caxambu-MG, 2006.

SILVA, T. T. A produção social da identidade e da diferença. In: SILVA, T. T. (Org.). Identidade e Diferença: a perspectiva dos estudos culturais. Petrópolis, RJ: Vozes, 2012. p. $73-102$.

SKLIAR, C. Pedagogia (improvável) da diferença: e se o outro não estivesse aí? Rio de Janeiro: DP\&A, 2003.

SOUSA SANTOS, B. Pela mão de Alice: o social e o político na pós-modernidade. São Paulo: Cortez, 2010.

WILLIAMS, J. Pós-estruturalismo. Petrópolis: Vozes, 2013. 